\title{
SCHOOL'S IMPORTANCE IN EMOTIONAL SUPPORT AND PEDAGOGICAL MANAGEMENT OF CHILDREN WITH ADHD
}

\author{
Katerina Lyberopoulou, \\ Sofia Tsolaki, \\ Paraskevi Ntereki, \\ Stefanos Armakolasi \\ Department of Education, \\ Higher School of Pedagogical \& \\ Technological Education, \\ Greece
}

\begin{abstract}
:
Attention-deficit hyperactivity disorder (ADHD) is one of the most commonly diagnosed conditions in children. It refers to symptoms such as inattention, impulsivity and hyperactivity that intervene in child's behavior and performance in school and home as well. ADHD is a frequently diagnosed mental disorder in children and adolescents. The aim of this research is to study teachers' knowledge of ADHD issue. Quantitative analysis was carried out for the purpose of this survey with the use of a questionnaire. Results showed that teachers are more familiar with the symptoms and definition of ADHD and less with its management at school. However, teachers' knowledge of ADHD seems to be adequate. Finally, the findings of this research point out that it is essential for teachers to be trained in terms of causes and intervention for this specific disorder.
\end{abstract}

Keywords: ADHD, school's importance, emotional support

\section{Introduction}

Attention-deficit hyperactivity disorder (ADHD) is estimated to affect about 5 - 7\% of preschool and school children (Barkley, 2005). Its main symptoms are inattention, hyperactivity and impulsiveness (Manos, 1997). A child is diagnosed with ADHD when symptoms appear before the age 7 for the duration of at least 6 months, child's developmental age is not typical of its age affecting child's functionality in more than two settings. Symptoms intervene in child's daily performance affecting many parts of its daily life: he/she may face difficulty to concentrate in school, has problems in following instructions, seems to be on constant motion, talks excessively, interrupts others, has no self-control and fails to start and complete a classroom activity. In more than $50 \%$ of

i Correspondence: email aspete patras@aspete.gr 
children diagnosed with ADHD the symptoms are still present in adolescence (Cuffe, Moore \& McKeown, 2005).

\subsection{Attention-deficit hyperactivity disorder (ADHD)}

For the past years scientific research and informational journalism have focused on Attention-deficit hyperactivity disorder (ADHD). ADHD is a common psychiatric disorder diagnosed in childhood with certain subtypes monitored. There have been differences in children describing various symptoms such as inattention, hyperactivity and impulsive behavior or a combination of them (Sherman, Rasmussen, \& Baydala, 2008). ADHD is a neurological developmental disorder estimated to affect $5-7 \%$ of children and adolescents. Students with ADHD display distractive behaviors in family or in school context. Most studies in ADHD have concluded that these fundamental symptoms have to do with deficits in executive functions. Only the parents of children with ADHD can understand differences in their children behavior compared to their peers since they fail to respond in the traditional pedagogical methods (Fabio, 2017). The diagnostic criteria for ADHD described at the most recent edition of the diagnostic and classification manual of the American Psychological Association (DSM- 5, 2013) are: a) Inattention, b) Hyperactivity and Impulsiveness (Pehlibanidis et al., 2012).

\subsection{Consequences in the psychological and emotional development and in school performance}

As already mentioned, a child with ADHD does not mean to behave the way he does and fails to handle with it. He/she can understand he is behaving inappropriately but is unable to control it. Therefore, if he is punished, criticized or treated in a hostile way in case of an unusual behavior he can fully understand it and gets upset or even reacts angrily. He is unable to control itself. Moreover, when he is treated as a "special" case from the people of his broad social environment (such as his peers) he can understand it (Koumoula, 2012).

He is definitely at greater risk of limited educational outcomes and school adjustment than the rest of the children in the classroom. He fails to keep up with the rest of the classroom and very often does not even try since he thinks that it makes no sense. It is not easy for him to socialize with the rest of his classroom since because of this disorder can cause distractions to the rest of the children. Not being aware of his problem the child with ADHD may end up isolated and excluded. He is also facing problems while working in a team / partner context (Fabio, 2017).

Thus, it is definite that the psychology of a child with ADHD is usually at a low point. He feels isolated, helpless and excluded because people around him due to their ignorance may treat him as "out of the ordinary".

\subsection{Teacher's role in diagnosing and evaluating ADHD}

Teachers are those who get in contact more often with the child or the adolescent in the classroom. Teachers observe students during class procedures, evaluate their academic 
performances, supervise them during class breaks, observe their overall social behavior and can come with conclusions regarding children's behavior in several activities under certain circumstances (Gelastopoulou et al., 2017).

Finally, medical professionals involved in evaluating children and adolescents with behavioral problems usually seek information from people involved in school, mainly teachers, because a child spends most of its time to school where he has to take part in school activities, to show its potential along with developing social relationships with its peers and the educational staff (Koumoula, 2012).

\subsection{Managing students with ADHD in classroom}

Students with ADHD perform poorly in school. One of the most important findings of the latest and long-term studies is that students with ADHD are at high risk of school failure and having to attend the same grade again. In some cases, they have to attend special needs schools or even drop out of school. Several studies have shown that the correlation between ADHD and low academic performance has its origins in early school stages. In order to manage students with ADHD in an efficient way several steps have to be followed. The most important of them are (Gelastopoulou et al., 2017):

- Emphasis at the curriculum,

- Analysis of the curriculum,

- Establishment of students' profile,

- Description of students' behavior in various situations or contexts,

- Objectives definition.

\section{Methodology}

The objective of this research is to study teachers' role and perceptions while dealing children with ADHD. This study employed a quantitative analysis of survey data with the use of a questionnaire. Research was guided by the following questions:

- Is there emotional support to children with ADHD in school?

- What is teacher knowledge about children with ADHD?

- How can a teacher treat students with ADHD?

Snowball sampling technique was used targeting at the fulfillment of 128 questionnaires. Snowball sampling procedure took place as follows: a random sample coming from a small pool of initial participants was used. These participants were asked to nominate other participants who met the eligibility criteria and could potentially contribute to the specific study. They could use their social network or their best friends in order to participate (Goodman, 1961). Although this sampling method seems to be unusual it is used in many scientific researches. The main reason for using this technique is that in many cases it is not possible to monitor the overall population for the desired sampling to be conducted along with the participation of analysis units (Iosifidis, 2008). At the current research 32 questionnaires were fulfilled. Sampling procedure took place in March 2020 for duration of 15 days. 
For the design of the questionnaire similar scientific studies were taken into account. Teachers' knowledge on ADHD was evaluated with the use of the ADHD Knowledge Based Questionnaire developed by McNicholas \& Santosh (1997). In the current research the Greek version translated and adjusted by Antonopoulou, Stampoltzi and Kouvava, (2010) was used. The researchers focused on using a short and comprehensive form, thus it consisted of closed ended questions. The questionnaire was divided in three sections:

- Section A: Demographics,

- Section B: ADHD knowledge (Questions B1 - B26),

- Section C: School management of ADHD knowledge (Questions C1 - C6),

At section B a 5 point Likert scale was used for responses: 1 = Strongly Disagree, 2 $=$ Disagree, 3 = Undecided, $4=$ Agree and $5=$ Strongly Agree .

The questionnaire was initially created as a word file and is attached at the current article appendix. The participation at the research was anonymous and confidential with all data collected used exclusively for the current research. Google Forms application was used for the online completion of the questionnaire.

\section{Results}

\subsection{Section A}

The survey sample consisted of 32 teachers for the Aigialeia province, who took part in the survey with the snowball sampling method. The participants' demographics are presented below. Sample characteristics are presented in the form of graphs and percentages:

Table 1: Sex of the participants

\begin{tabular}{|c|l|c|c|c|c|}
\hline \multicolumn{2}{|c|}{} & Frequency & Percentage & Valid Percentage & Cumulative Percentage \\
\hline \multirow{3}{*}{ Valid } & Male & 3 & 9,4 & 9,4 & 9,4 \\
\cline { 2 - 6 } & Female & 29 & 90,6 & 90,6 & 100,0 \\
\cline { 2 - 6 } & Total & 32 & 100,0 & 100,0 & \\
\hline
\end{tabular}

According to the data displayed in table 1, 32 teachers took part in the current research. The majority of them were female (29) forming a percentage of $90,6 \%$ while the rest were male ( 3 individuals forming $9,4 \%$ of the sample).

Table 2: Age of the participants

\begin{tabular}{|c|l|c|c|c|c|}
\hline \multicolumn{2}{|c|}{} & Frequency & Percentage & Valid Percentage & Cumulative Percentage \\
\hline \multirow{4}{*}{ Valid } & $26-35$ years & 21 & 65,6 & 65,6 & 65,6 \\
\cline { 2 - 6 } & $36-45$ years & 7 & 21,9 & 21,9 & 87,5 \\
\cline { 2 - 6 } & $46-55$ years & 4 & 12,5 & 12,5 & 100,0 \\
\cline { 2 - 6 } & Total & 32 & 100,0 & 100,0 & \\
\hline
\end{tabular}




\subsection{Section B}

The descriptive analysis displays the absolute and relevant frequencies of the questionnaire responses in tables along with point values and data dispersion. The average and the absolute value ware used to display the point values while the standard deviation was used to display data dispersion. In the table above the percentages of the responses at the questions of section $B$ are presented.

Table 3: Section B - Descriptive Analysis

\begin{tabular}{|c|c|c|c|c|c|}
\hline \multicolumn{6}{|l|}{ Section B (Version $1 \eta$ ) } \\
\hline & $\begin{array}{l}\text { Strongly } \\
\text { Disagree }\end{array}$ & Disagree & Undecided & Agree & $\begin{array}{l}\text { Strongly } \\
\text { Agree }\end{array}$ \\
\hline $\begin{array}{l}\text { B1. ADHD occurs in about } 5 \% \text { of school going } \\
\text { children. }\end{array}$ & $3.10 \%$ & $12.50 \%$ & $40.60 \%$ & $34.40 \%$ & $9.40 \%$ \\
\hline $\begin{array}{l}\text { B2. ADHD symptoms may occur even in } 2 \text { years } \\
\text { old children. }\end{array}$ & $6.30 \%$ & $15.60 \%$ & $40.60 \%$ & $21.90 \%$ & $15.60 \%$ \\
\hline $\begin{array}{l}\text { B3. Children usually overcome ADHD at the age } \\
\text { of } 10\end{array}$ & $62.50 \%$ & $18.80 \%$ & $3.10 \%$ & $15.60 \%$ & $0 \%$ \\
\hline $\begin{array}{l}\text { B4. Children with ADHD are popular in the } \\
\text { classroom. }\end{array}$ & $12.50 \%$ & $18.80 \%$ & $37.40 \%$ & $21.90 \%$ & $9.40 \%$ \\
\hline B5. Girls are more often diagnosed with ADHD. & $40.60 \%$ & $53.20 \%$ & $3.10 \%$ & $3.10 \%$ & 0 \\
\hline $\begin{array}{l}\text { B6. Children with ADHD are seldom distracted } \\
\text { from their activity. }\end{array}$ & $71.90 \%$ & $15.60 \%$ & $6.30 \%$ & $3.10 \%$ & $3.10 \%$ \\
\hline $\begin{array}{l}\text { B7. Medication is often very effective in the } \\
\text { control of ADHD symptoms. }\end{array}$ & $31.30 \%$ & $18.80 \%$ & $34.30 \%$ & $12.50 \%$ & $3.10 \%$ \\
\hline $\begin{array}{l}\text { B8. ADHD is identified automatically as a special } \\
\text { needs category }\end{array}$ & $9.40 \%$ & $9.40 \%$ & $21.80 \%$ & $25.00 \%$ & $34.40 \%$ \\
\hline $\begin{array}{l}\text { B9. Children with ADHD seldom appear to be } \\
\text { aggressive or behave inappropriately. }\end{array}$ & $25.00 \%$ & $46.80 \%$ & $18.80 \%$ & $3.10 \%$ & $6.30 \%$ \\
\hline $\begin{array}{l}\text { B10. Dietary constituents such as food colorings } \\
\text { and preservatives are responsible for ADHD }\end{array}$ & $25.00 \%$ & $21.90 \%$ & $28.10 \%$ & $21.90 \%$ & $3.10 \%$ \\
\hline $\begin{array}{l}\text { B11. ADHD symptoms change while the child } \\
\text { grows. }\end{array}$ & $6.20 \%$ & $9.40 \%$ & $50.00 \%$ & $31.30 \%$ & $3.10 \%$ \\
\hline $\begin{array}{l}\text { B12. Children with ADHD are restless, constantly } \\
\text { moving and are unable to stand still. }\end{array}$ & $3.10 \%$ & $0.00 \%$ & $3.10 \%$ & $43.80 \%$ & $50.00 \%$ \\
\hline B13. ADHD often runs in families. & $9.40 \%$ & $37.50 \%$ & $37.50 \%$ & $9.40 \%$ & $6.20 \%$ \\
\hline $\begin{array}{l}\text { B14. ADHD is a label used as an excuse for badly } \\
\text { behaved children. }\end{array}$ & $21.80 \%$ & $25.00 \%$ & $34.40 \%$ & $9.40 \%$ & $9.40 \%$ \\
\hline $\begin{array}{l}\text { B15. Pharmaceutical treatment (i.e. ritalin) usually } \\
\text { delays child development. }\end{array}$ & $6.20 \%$ & $18.80 \%$ & $65.60 \%$ & $9.40 \%$ & $0.00 \%$ \\
\hline $\begin{array}{l}\text { B16. Antidepressants are sometimes used in the } \\
\text { treatment of ADHD. }\end{array}$ & $18.80 \%$ & $18.80 \%$ & $46.80 \%$ & $12.50 \%$ & $3.10 \%$ \\
\hline $\begin{array}{l}\text { B17. Medication for ADHD must be used for } \\
\text { periods when the child is very naughty. }\end{array}$ & $12.50 \%$ & $28.10 \%$ & $59.40 \%$ & $0.00 \%$ & $0.00 \%$ \\
\hline B18. Poor parenting practices may cause ADHD. & $34.40 \%$ & $21.90 \%$ & $21.90 \%$ & $15.60 \%$ & $6.20 \%$ \\
\hline $\begin{array}{l}\text { B19. A child that displays hyperactivity at but not } \\
\text { in school cannot have ADHD }\end{array}$ & $18.80 \%$ & $15.60 \%$ & $37.50 \%$ & $21.90 \%$ & $6.20 \%$ \\
\hline $\begin{array}{l}\text { B20. Children with ADHD intervene in others' } \\
\text { discussions and talk excessively. }\end{array}$ & $0.00 \%$ & $12.50 \%$ & $34.40 \%$ & $31.30 \%$ & $21.80 \%$ \\
\hline $\begin{array}{l}\text { B21. The majority of children with ADHD are } \\
\text { described by the teachers as children with } \\
\text { behavioral problems. }\end{array}$ & $0.00 \%$ & $3.10 \%$ & $9.40 \%$ & $62.50 \%$ & $25.00 \%$ \\
\hline $\begin{array}{l}\text { B22. Children with ADHD do better in situations } \\
\text { which are less structured. }\end{array}$ & $49.90 \%$ & $18.80 \%$ & $12.50 \%$ & $18.80 \%$ & $0.00 \%$ \\
\hline
\end{tabular}



MANAGEMENT OF CHILDREN WITH ADHD

\begin{tabular}{|l|c|c|c|c|c|}
\hline \hline $\begin{array}{l}\text { B23. Children with ADHD usually have low self- } \\
\text { esteem. }\end{array}$ & $0.00 \%$ & $12.50 \%$ & $28.10 \%$ & $\mathbf{3 7 . 5 0} \%$ & $21.90 \%$ \\
\hline $\begin{array}{l}\text { B24. ADHD is thought to result from } \\
\text { neurochemical disturbances in the brain. }\end{array}$ & $0.00 \%$ & $9.40 \%$ & $34.40 \%$ & $\mathbf{4 3 . 7 0} \%$ & $12.50 \%$ \\
\hline $\begin{array}{l}\text { B25. Children with ADHD work in a hurry and } \\
\text { make mistakes due to carelessness. }\end{array}$ & $0.00 \%$ & $3.10 \%$ & $12.50 \%$ & $\mathbf{4 6 . 9 0 \%}$ & $37.50 \%$ \\
\hline $\begin{array}{l}\text { B26. Family factors are less important than } \\
\text { biological factors in ADHD causes. }\end{array}$ & $12.50 \%$ & $34.40 \%$ & $\mathbf{4 0 . 6 0 \%}$ & $12.50 \%$ & $0.00 \%$ \\
\hline
\end{tabular}

The results presented at Table 3 show that in several cases the majority of the participants stated that they Strongly Agree whilst in others they stated that they Strongly Disagree. There is also a group of questions where the participants stated that they are Undecided. The participants stated that they Strongly Disagree in the following questions: question B3 where $62.5 \%$ of the participants stated that Children usually overcome ADHD at the age of 10 along with the question B6 which referred to Children with ADHD being seldom distracted from their activity (71.9\%). Moreover, $49.9 \%$ percent of the participants stated that they Strongly Disagree that Children with ADHD do better in situations which are less structured (B22). 53.2\% of the participants stated that they Strongly Disagree with the statements at question B5 which refers to Girls being more often diagnosed with ADHD. The questions where the majority of the participants were Undecided are: B11 which refers to ADHD symptoms changing while the child grows, B15 which refers to the delay Pharmaceutical treatment may cause to child development and B17 which has to do with the assumption that Medication for ADHD must be used only for periods when the child is very naughty. The participants stated that they Strongly Agree that the majority of children with ADHD are described by the teachers as children with behavioral problems (B21) and that Children with ADHD are restless, constantly moving and are unable to stand still (B12). In a few questions the participants stated that they either Strongly agree, remain Undecided or Strongly Disagree in a very small ratio (less than $15 \%$ ). The analysis of these questions is presented as follows:

The questions where the minority of the participants stated that they Strongly Disagree refer to the age ADHD symptoms may occur and change while the child grows (B2, B11). The responses where strong disagreement was monitored in the smallest percent referred to Children with ADHD being popular in the classroom, being restless, constantly moving and are unable to stand still and that ADHD often runs in families. The smallest ratio of the participants stated that they Disagree with the questions referring to diagnosis of ADHD and their abilities in socialization and hyperactivity. The participants stated in smallest ratio that they are undecided in their responses at the questions that had to do with the frequency of ADHD diagnosis according to sex, the age when ADHD symptoms no longer exist and teachers' management of children with ADHD. There were a few questions such as the sex of children with ADHD in the highest percentage, the role of genetics and various behavioral patterns of children with ADHD where the participants stated in a very small ratio that they Agree or Strongly Agree. The analysis of the responses shows that there is no variance at the participants' statements. 
The participants' responses were further analyzed and the percentage of cases where they stated that they Strongly Disagree and Disagree was added in order to monitor if the cumulative result is greater than $75 \%$. The same analysis was conducted for the cases where they stated that they Strongly Agree and Agree. The questions where the participants stated Disagreement in a cumulative percentage greater than $75 \%$ were:

- B3. Children usually overcome ADHD at the age of $10(81.3 \%)$.

- B5. Girls are more often diagnosed with ADHD (93.8\%).

- B6. Children with ADHD are seldom distracted from their activity (87.5\%).

The questions where the participants stated Agreement in a cumulative percentage greater than $75 \%$ were:

- B12. Children with ADHD are restless, constantly moving and are unable to stand still $(93.8 \%)$.

- B21. The majority of children with ADHD are described by the teachers as children with behavioral problems (87.5\%).

- B25. Children with ADHD work in a hurry and make mistakes due to carelessness $(84.4 \%)$.

\subsection{Section C}

The questions referring to management of children with ADHD are presented in section C:

According to the data gathered and are displayed in the following table with the exception of one of the participants the rest of them consisting a very high percentage $\mathbf{( 9 6 . 9 \% )}$ stated that if in their classroom there were children with ADHD, they would modify their way of teaching in order for these children to be able to take part in classroom activities in an efficient way.

Table 4: Percentage of teachers that would modify

their way of teaching in case of a child with ADHD

\begin{tabular}{|l|l|c|c|c|c|}
\hline \multicolumn{2}{|l|}{ C1 } & Frequency & Percentage & Valid Percentage & Cumulative Percentage \\
\hline \multirow{3}{*}{ Valid } & Yes & 31 & 96.9 & 96.9 & 96.9 \\
\cline { 2 - 6 } & No & 1 & 3.1 & 3.1 & 100.0 \\
\cline { 2 - 6 } & Total & 32 & 100.0 & 100.0 & \\
\hline
\end{tabular}

The main reasons mentioned from the participants about modifying their teaching practices are:

- In order for the child with ADHD to adjust in the classroom and to be able to participate with the rest of the children in school activities.

- Children with ADHD need attention and their interest in classroom has to be stimulated. This can be achieved through audiovisual activities that motivate him/her to participate. 
- When children with ADHD are involved in activities that stimulate them, their behavior is less distractive which leads to an overall improved classroom teaching condition.

- Children with ADHD operate more effectively when being in a context. Thus, if teaching is adjusted to their situation their performance as well as that of their peers is increased.

Regarding the placement of a student with ADHD in classroom the results of the current survey showed:

Table 5: How the seating arrangement of a child with ADHD should be

\begin{tabular}{|l|c|}
\hline C2 & \\
\hline Choices & Percentage \\
\hline a. Place the student in front in proximity with the teacher. & $15.6 \%$ \\
\hline b. Place the student in the middle of the classroom & $6.3 \%$ \\
\hline c. Place the student in the back of the classroom & $0.0 \%$ \\
\hline d. Place the student away from distractions such as posters, photographs, windows. & $6.3 \%$ \\
\hline e. a \& d & $65.6 \%$ \\
\hline f. c \& d & $6.3 \%$ \\
\hline
\end{tabular}

This study's findings show that according to teachers' perceptions, children with ADHD must be seated in front, in the proximity of the teacher and away from audiovisual means that could distract him/her. These seating arrangements practices contribute in enhancing him/her concentrate more.

According to this study's findings all participants agreed that the amount of homework intended for children with ADHD should be the same with the rest of their peers. Since children with ADHD need more time in order to complete an assignment, it must not excess this intended for the typically developed students.

Table 6: The amount of homework intended for children with ADHD should not excess this intended for the typically developed students

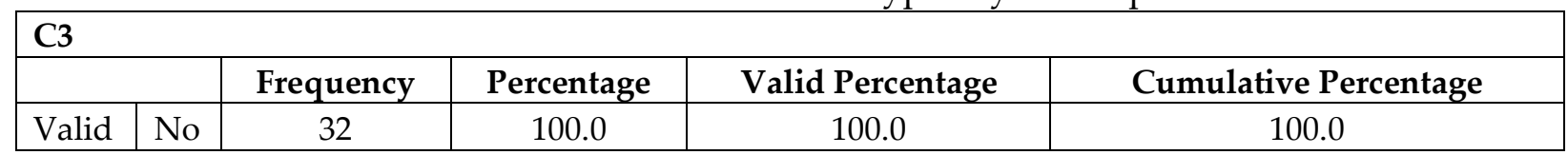

As far as the instructions to be given to children with ADHD and the way they should be addressed the participants stated as follows:

Table 7: How the teachers should give directions to children with ADHD

\begin{tabular}{|l|c|}
\hline C4 & \\
\hline Choices & Percentage \\
\hline a. The instructions must be given in a short, clear and simple way & $15.6 \%$ \\
\hline b. The instructions must be repeated often. & $18.8 \%$ \\
\hline c. The instructions must be given the same way with the rest of the students & $3.1 \%$ \\
\hline d. a \& b & $62.5 \%$ \\
\hline e. b \& c & $0.0 \%$ \\
\hline
\end{tabular}


According to teachers' perceptions it is clear that the instructions must be given in a short, clear and simple way and when this is necessary, they must be repeated for all children to be able to understand.

3 out of 4 participants (75\%) consider that the questions and activities addressed to children with ADHD must be structured the same way with questions / activities addressed to all students while the $25 \%$ of the participants in the current study believe that they should be less structured.

Table 8: Activities addressed to children with ADHD should be less structured

\begin{tabular}{|l|l|c|c|c|c|}
\hline \multicolumn{2}{|l|}{ C5 } & Frequency & Percentage & Valid Percentage & Cumulative Percentage \\
\hline \multirow{3}{*}{ Valid } & Yes & 8 & 25.0 & 25.0 & 25.0 \\
\cline { 2 - 6 } & No & 24 & 75.0 & 75.0 & 100.0 \\
\cline { 2 - 6 } & Total & 32 & 100.0 & 100.0 & \\
\hline
\end{tabular}

As far as managing students with ADHD teachers' perceptions recorded were:

Table 9: Teacher's interventions for managing a child with ADHD

\begin{tabular}{|l|c|}
\hline Teachers should: & Percentage \\
\hline a. keep the child with ADHD seated in order not to be distracted & $3.1 \%$ \\
\hline b. allow the child with ADHD to move whilst in his seat but setting clear limits & $18.8 \%$ \\
\hline c. assign tasks to child with ADHD in order to alleviate its hyperactivity & $12.5 \%$ \\
\hline d. b \& c & $59.4 \%$ \\
\hline e. a \& c & $6.3 \%$ \\
\hline
\end{tabular}

The responses showed that the majority of teachers would allow the student with ADHD to move whilst in his seat but setting clear limits and to assign tasks in order to alleviate its hyperactivity.

\section{Analysis}

As far as the first research question is concerned, the emotional evolution of students with ADHD is affected by two factors: the way teachers manage them and whether they are able to get involved in classroom activities. If teachers manage effectively a student with ADHD and pay attention to his strengths and needs, this will enhance student's academic performance and increase his self - esteem. Since students with ADHD spend a lot of time in the classroom, teachers play a significant role in forming student's mentality and social performance. Teachers' perceptions in the first research question are responded in section $\mathrm{B}$ of the questionnaire.

As already mentioned, teachers' knowledge of ADHD is limited. They are not thoroughly informed about which are the possible causes of ADHD and about how they should manage a student with ADHD. If they were better informed, they would be able to facilitate the student's life along with enhancing the educational process. Teachers' responses to second research question show that their knowledge about ADHD 
symptoms, their variance and the effects of pharmaceutical treatment of ADHD is insufficient. They must be trained more sufficiently because if they know how to manage a student with ADHD, they will be able to establish positive relationships with students improving lives for both students and teachers and facilitate learning.

According to the responses at section $\mathrm{C}$ of the questionnaire referring to the third research question no variance was recorded. When teachers have to handle students with ADHD, teaching practices have to be adjusted in order to enhance their involvement in classroom activities. Moreover, successful management of students with ADHD results in being less distracted. According to this survey findings, students with ADHD must be placed in front, in proximity with teachers, as far as possible from audiovisual distractions. Furthermore, teachers must give clear, well-structured instructions and repeat them whenever is necessary. Learning process will be facilitated if students with ADHD along with the other students operate through a behavioral context and certain rules are applied.

\section{Discussion and Conclusion}

From the analysis mentioned above it is obvious that children with ADHD form a significant percent in the educational community. The current research's findings focused on the First Degree Education and if they are combined with the existing literature in this subject, suggest that many things have to be improved in the future.

According to our findings, the participants lacked profound knowledge of several aspects concerning ADHD students' management. Their knowledge about symptoms, age of diagnosis, genetic factors and presentations of ADHD is insufficient. However, it must be pointed out that preschool and primary school teachers are usually the first to monitor student's behavior implying the presence of ADHD because its presentations are easier to be identified in school. The aforementioned assumption marks the necessity of immediate and proper training of teachers about the strengths and needs of students with ADHD in order to manage them in a direct and efficient way.

The findings of the current research come in terms with the assumptions made by Kakourou, Papailiou and Badikian (2006) about teachers' insufficient knowledge on ADHD although they are the first asked to identify, diagnose and manage children with this disorder. Thus, it is implied that there should be lifelong training of teachers in general and special issues about ADHD. West et al., (2005) point out the necessity for lifelong training of teachers since there is a lot of research on ADHD and new scientific and data emerge constantly. If we take into account that the latest policies and practices in education enhance the inclusion of students with ADHD and children with special needs in general education, it is vital that teachers must be aware of the primary and secondary constraints of children with ADHD and its correlation to other disorders.

When teachers are more aware and educated on ADHD issues, the educational process is easier and more effective. It is suggested that special needs courses and psychopathology lessons should be included in teachers' curriculum during their basic 
academic studies. The main objective of the educational system should be the integration of children with this disorder along with the facilitation of the academic process both for educators and students. Students with ADHD possess special strengths and are capable of learning in a different way from their peers. They need attention and care by their teachers. They must not be excluded, and teachers must make good use of their potential.

\section{About the Authors}

Aikaterini Lymperopoulou is a graduate Nurse of Technological Educational Institute of Patras since 2009. And she has a Master Degree of University of Peloponnese, in the field: Administration of Services of Health and Management of Crises. She has worked as a nurse in "Help at home" and as a school nurse at Patras. Now she is working in Public Health and Primary Care working in different primary health care settings. In 2020 she received her Certificate in pedagogical training from the School of Pedagogical and Technological Education (ASPETE).

Sofia Tsolaki is a Social Worker holding a degree from the Department of Social Work of the Higher Technological and Educational Institute of Patras (ATEI of Patras) ,Greece since 2005. She is a certified Parents Group Educator from the Panhellenic Parent Education Groups' Association and a certified Adult Group Educator from the Hellenic Open University (EAP) and INEDIVIM (Youth and Lifelong Learning Foundation). She holds a certificate of Sufficiency in the Greek Sign Language from the Hellenic Federation of the Deaf since 2010. In 2019 she graduated from Logo Psychis - Training and Research Institute for Systemic Psychotherapy - as a Systemic Psychotherapist and she also graduated from the Higher School of Pedagogical and Technological Education (ASPETE). She has work experience in the following fields: Female Child Care Center of Patras, National Institute for the Deaf - Department of Patras, Parents Group Educator in Patras, Child Care Center, PRAKSIS - Emergency Response and Relocation Scheme, Rental of Apartments with the UNHCR, Institute of Child Care and LUMOS "Study for the Care of Vulnerable Children I Greece, LUMOS DeInstitutionalization grogram". The last three years she works for the Ministry of Education and Religious Affairs as a School Social Worker by offering consulting, evaluation and support services to students, parents and teachers.

Paraskevi Ntereki has had a degree in Accountancy from the Technological Institution of Patras since 1999. In 2020 she received her Certificate in pedagogical training from the School of Pedagogical and Technological Education (ASPETE). She has attended various seminars including Special Education and Adult Learning. Her job experience includes working as an office assistant for 10 years.

Stefanos Armakolas has been a member of the instructional Laboratory Personnel at the Department of Education of the Higher School of Pedagogical \& Technological Education (ASPETE) since 2006.He also is a tutor at Hellenic Open University. He holds a B.Sc. from Dept. of Technological Applications of Technological Educational Institute of Piraeus, and Master in Education from Dept. of Humanities of Hellenic Open University. His teaching experience includes teacher education and training on these topics: Teaching 
Practical Exercises, Educational Technology, Pedagogical Applications with New

Technologies. He holds a PhD at the Department of Education and Social work of University of Patras orcid.org/0000-0003-1264-7066.

\section{References}

Antonopoulou, A., Stampoltzi, A., Kouvava, S. (2010). Teachers' knowledge about Attention-deficit hyperactivity disorder (ADHD) (in Greek). Teacher Issues Review, $16,162-180$.

Barkley, R., A. (2005). Attention-Deficit Hyperactivity disorder: A handbook for diagnosis and treatment ( $3^{\text {rd }}$ ed.), New York: Guilford Press.

Chiang, H. L., Gau, S. S., Ni, H. C., Chiu, Y. N., Shang, C. Y., Wu, Y. Y., Lin, L. Y., Tai, Y. M., \& Soong, W. T. (2010). Association between symptoms and subtypes of attention-deficit hyperactivity disorder and sleep problems/disorders. J Sleep Res, 19(4), 535-45.

Fabio, R. A. (2017). The study of automatic and controlled processes in ADHD: a reread and a new proposal. Mediterranean Journal of Clinical Psychology, 5(1).

Fabio, R. A., Castriciano, C., \& Rondanini, A. (2015). ADHD: Auditory and Visual Stimuli in Automatic and Controlled Processes. Journal of Attention Disorder, 19, 771-778.

Gelastopoulou, M., Imellou, O., Vlachou, A., Moutavelis, A., Asteri, Th-N., Galanis, P., Iliakopoulou, A., Skaloumpakas, X., Bousdounis, I, Girtis, K., Georgakakou, S., Koutras, S., Papakonstantinou, S. (2017). Teaching material for the support and integration of students with special needs in school. (in Greek) Athens, Educational Policy Institute.

Goodman La (1961). Snowball sampling. Annals of Mathematical. Statistics 32,148-170.

Kakouros, E, Papailiou, X., Badikian, M. (2006). Teachers' perceptions on their importance treating children with Attention-deficit hyperactivity disorder (ADHD) (in Greek). Pedagogical Review, 41, 117-130.

Koumoula, A. (2012). The evolution of Attention-deficit hyperactivity disorder (ADHD) over time.(in Greek). Psychiatric, 23(1), 49-59.

Manos, N. (1997). Basic Clinical Psychiatric Elements. (in Greek). Thessaloniki: University Studio Press.

Miranda, A., Presentación, M. J., Castellar, R. G., \& Siegenthaler, R. (2009). Intervention with students with ADHD: Analysis of the effects of a multi-component and multicontextualized program on academic and socio-emotional adjustment. Advances in Learning and Behavioral Disabilities, 22, 227-263.

Pehlivanidis, A., et al., (2012). Attention-deficit hyperactivity disorder (ADHD) in adults. Identification, diagnosis and treatment. (in Greek). Greek Medicine Archives, 29(5): $562-576$.

Pervanidou, P. (2009). Genetic and Environmental Risk Factors in Attention-deficit hyperactivity disorder (ADHD). (in Greek). Research team for ADHD: Data from 
National and Greek Literature, 6o Panhellenic Conference in Child Psychiatrics, 15 - 17 May 2009, Athens

Sherman, J., Rasmussen, C., \& Baydala, L. (2008). The impact of teacher factors on achievement and behavioural outcomes of children with Attention Deficit/ Hyperactivity Disorder (ADHD): a review of the literature. Educational Research, 50(4), 347-360.

Theeuwes J., Kramer A. F., Irwin D. E. (2011). Attention on our mind: The role of spatial attention in visual working memory. Acta Psychologica, 137(2), 248-251.

Wang, Q., Bernas, R. \& Eberhard, P. (2004). Engaging ADHD students in tasks with hand gestures: A pedagogical possibility for teachers. Educational Studies, 30, 217-229.

Zentall, S. S. (1993). Research on the educational implications of attention deficit hyperactivity disorder. Exceptional Children, 60(2), 143-153. 
Creative Commons licensing terms

Authors will retain the copyright of their published articles agreeing that a Creative Commons Attribution 4.0 International License (CC BY 4.0) terms wil be applied to their work. Under the terms of this license, no permission is required from the author(s) or publisher for members of the community to copy, distribute, transmit or adapt the article content, providing a proper, prominent and unambiguous attribution to the authors in a manner that makes clear that the materials are being reused under permission of a Creative Commons License. Views, opinions and conclusions expressed in this research article are views, opinions and conclusions of the author(s). Open Access Publishing Group and European Journal of Special Education Research shall not be responsible or answerable for any loss, damage or liability caused in relation to/arising out of conflict of interests, copyright violations and inappropriate or inaccurate use of any kind content related or integrated on the research work. All the published works are meeting the Open Access Publishing requirements and can be freely accessed, shared, modified, distributed and used in educational, commercial and non-commercial purposes under a Creative Commons Attribution 4.0 International License (CC BY 4.0). 